\title{
COMPARISON OF IN-HOSPITAL OUTCOME OF PATIENTS OF MYOCARDIAL INFARCTION WITH AND WITHOUT STREPTOKINASE REPERFUSION THERAPY.
}

1. MBBS, MCPS (Medicine), FCPS (Cardiology)

Assistant Professor Cardiology

Sargodha Medical College, University of Sargodha.

2. MBBS, MCPS (Medicine),

FCPS (Medicine)

Associate Professor Medicine

Sargodha Medical College,

University of Sargodha.

3. MBBS, MCPS (Medicine),

FCPS (Medicine)

Assistant Professor Medicine

Sargodha Medical College,

University of Sargodha.

4. MBBS, MCPS (Medicine),

FCPS (Medicine)

Senior Registrar Medicine

Sargodha Medical College,

University of Sargodha.

5. MBBS, MCPS (Medicine),

FCPS (Cardiology)

Assistant Professor Cardiology

Sargodha Medical College,

University of Sargodha.

Correspondence Address:

Dr. Fida Muhammad

Department of Cardiology

Sargodha Medical College,

University of Sargodha.

mfida73@yahoo.com

Article received on:

$12 / 03 / 2020$

Accepted for publication:

$17 / 06 / 2020$

\section{INTRODUCTION}

Myocardial infarction (MI) is the commonest medical emergency worldwide., ${ }^{1,2}$ Globally, it is also most common cause of mortality above the age of 60 years and its rate is increasing day by day. ${ }^{3,4}$ Risk of cardiovascular disease increases with advancing age. ${ }^{5}$ Important risk factors that are responsible for acute coronary syndrome are hypertension, diabetes and hyperlipidemia. ${ }^{6}$

Acute myocardial infarction being the life threatening condition, demands immediate emergency treatment that includes reperfusion therapy. ${ }^{7,8}$ Fibrinolysis remains the choice of treatment for myocardial infarction wherever circumstances for percutaneous coronary intervention are not favorable. ${ }^{9,10} \mathrm{~A}$ well renowned indirect fibrinolytic agent is "streptokinase" (SK). ${ }^{11}$ Administration of SK in acute MI lowers the risk of mortality however it is associated with hypotension and hemorrhage. ${ }^{12}$

As Streptokinase is linked to adverse effects, the purpose of this study was to compare the inhospital outcome with and without reperfusion therapy with streptokinase among patients with myocardial infarction. This study would help in establishing recommendations about the use of streptokinase in acute myocardial infarction.

\section{MATERIAL \& METHODS}

This prospective study was conducted in the 
Cardiology Department, Divisional headquarter teaching, Hospital, Sargodha from March 2018 to December 2018. The study included 300 patients with acute myocardial infarction of either gender and above 20 years of age. Patient with acute myocardial infarction were diagnosed by raised cardiac enzymes and ST elevation on ECG. Patient with non-ST elevation MI, cardiac, hepatic and renal failure and previous arrhythmias were excluded from the study. Patients were divided into two groups.

Group I (SK Group): patients received SK $(1500000 / \cup)$ who reported in less than six hours because of indication to SK $(n=180)$.

Group II (Non-SK group): patient who didn't receive SK because of either contraindication to SK or due to late presentation $(n=120)$.

Demographic features, history and physical

\begin{tabular}{|c|c|c|c|c|c|c|}
\hline \multicolumn{5}{|c|}{ Variables } & \multicolumn{2}{|c|}{ No. of Patients (\%) } \\
\hline \multirow{2}{*}{\multicolumn{2}{|c|}{ Age (years) }} & \multicolumn{3}{|c|}{ Mean \pm SD } & \multicolumn{2}{|c|}{$55.61 \pm 11.35$} \\
\hline & & \multicolumn{3}{|c|}{ Range } & \multicolumn{2}{|c|}{$25-60$} \\
\hline \multirow{2}{*}{\multicolumn{2}{|c|}{ Gender }} & \multicolumn{3}{|c|}{ Male } & \multicolumn{2}{|c|}{$228(76.0 \%)$} \\
\hline & & \multicolumn{3}{|c|}{ Female } & \multicolumn{2}{|c|}{$72(24.0 \%)$} \\
\hline \multirow{2}{*}{\multicolumn{2}{|c|}{ Co-morbidities }} & \multicolumn{3}{|c|}{ Diabetes mellitus } & \multicolumn{2}{|c|}{110 (36.67\%) } \\
\hline & & \multicolumn{3}{|c|}{ Hypertension } & \multicolumn{2}{|c|}{$220(73.34 \%)$} \\
\hline \multicolumn{5}{|l|}{ Smoking } & \multicolumn{2}{|c|}{$105(35.0 \%)$} \\
\hline \multicolumn{5}{|c|}{ Family history of IHD } & \multicolumn{2}{|c|}{85 (28.34\%) } \\
\hline \multicolumn{7}{|c|}{ Table-I. Characteristics of patients $(n=300)$} \\
\hline \multicolumn{3}{|c|}{ Parameters } & $\begin{array}{c}\text { SK Group } \\
(n=180)\end{array}$ & $\begin{array}{c}\text { Non SK Group } \\
(n=120)\end{array}$ & Total & P-Value \\
\hline \multicolumn{3}{|c|}{ In-hospital Mortality } & $12(6.6 \%)$ & $38(31.6 \%)$ & $50(16.67 \%)$ & $<0.001^{*}$ \\
\hline \multirow{10}{*}{ Complications } & \multicolumn{2}{|l|}{ Left ventricular failure } & $15(8.33 \%)$ & $28(23.33 \%)$ & $43(14.34 \%)$ & $<0.001^{*}$ \\
\hline & \multicolumn{2}{|l|}{ Mitral regurgitation } & $2(1.11 \%)$ & $3(2.5 \%)$ & $5(1.67 \%)$ & 0.848 \\
\hline & \multicolumn{2}{|l|}{ VT/VF } & $6(3.33 \%)$ & $7(5.83 \%)$ & $13(4.34 \%)$ & 0.297 \\
\hline & \multicolumn{2}{|c|}{ Complete heart block } & $4(2.22 \%)$ & $7(5.83 \%)$ & $11(3.67 \%)$ & 0.103 \\
\hline & \multicolumn{2}{|l|}{ Atrial fibrillation } & $1(0.55 \%)$ & $2(1.67 \%)$ & $3(1.0 \%)$ & 0.343 \\
\hline & \multicolumn{2}{|l|}{ Post MI angina } & $6(3.33 \%)$ & $16(13.33 \%)$ & $22(7.34 \%)$ & $0.001^{*}$ \\
\hline & \multicolumn{2}{|l|}{ Re-infarction } & $2(1.11 \%)$ & $4(3.33 \%)$ & $6(2.0 \%)$ & 0.178 \\
\hline & \multicolumn{2}{|l|}{ CVA } & $1(0.55 \%)$ & $0(0.0 \%)$ & $1(0.34 \%)$ & 0.812 \\
\hline & Ventral septal defec & & $0(0.0 \%)$ & $4(3.33 \%)$ & $4(1.34 \%)$ & $0.029^{*}$ \\
\hline & Hypotension & & $45(25 \%)$ & $10(8.33 \%)$ & $55(18.34 \%)$ & $<0.001 *$ \\
\hline & Table-II. In-hospital & al ou & $\begin{array}{r}\text { ne of patien } \\
* \mathrm{Si}\end{array}$ & and without & kinase $(n=3$ & \\
\hline
\end{tabular}

Characteristics of patients are shown in Table-I.

The male to female ratio was $3.1: 1$. The most
common co-morbidity was hypertension i.e.
$73.34 \%$. In-hospital outcome of patients with and

The male to female ratio was $3.1: 1$. The most
common co-morbidity was hypertension i.e.
$73.34 \%$. In-hospital outcome of patients with and

The male to female ratio was $3.1: 1$. The most
common co-morbidity was hypertension i.e.
$73.34 \%$. In-hospital outcome of patients with and without streptokinase is shown in Table-II.

\section{DISCUSSION}

This study was conducted to compare the inhospital outcome and complications with and without reperfusion therapy with streptokinase among patients with myocardial infarction, which included 300 cases. examination were noted. All patients were monitored according to CCU protocol. In hospital mortality and complications were recorded and compared between groups by chi square test taking $p$ value $\leq 0.05$ as significant. The data was entered into SPSS version 20, computer program and analyzed accordingly.

\section{RESULTS} . 
In our study the mean age of the patients was $55.61 \pm 11.35$ years (Range: $25-60$ ). Similarly, in a study by Taheri $L$ et $\mathrm{al}^{13}$, mean age of patients was $56.63 \pm 11.04$ years. In another study by Uddin F and Hoque $\mathrm{FAK}^{14}$, the mean age of patient was $55.79 \pm 13.11$ years. It shows that coronary heart disease is shifting to very early age in this part of world. This similarity was also observed by Roxana Sadeghi and Nadia Adnani. ${ }^{15}$ There was male dominance in our study, i.e. $76.0 \%$ male with male to female ratio of 3.1:1. Similar to our study, male dominance was also observed in a study by Taheri $\mathrm{L}$ et $\mathrm{al}^{13}$, i.e. $61.67 \%$. In another study by Uddin $\mathrm{F}$ and Hoque $\mathrm{FAK}^{14}$, $75.0 \%$ patients were male.

Family history of ischemic heart disease was present in $28.34 \%$ patients, in our study. In a study by Uddin $\mathrm{F}$ and Hoque FAK $^{14}$, family history of ischemic heart disease was present in $33.2 \%$ patients with acute Ml. In our study, the most common co-morbidity was hypertension i.e. $73.34 \%$, followed by diabetes mellitus i.e. $36.67 \%$. Similarly, in a study by Taheri L et al ${ }^{13}$, commonest co-morbidity was hypertension (14.7\%), followed by heart ischemia (11.3\%), diabetes (8.7\%) and hyperlipidemia (1.0\%). However, in a study by Uddin $\mathrm{F}$ and Hoque $\mathrm{FAK}^{14}$, the most common comorbidity was diabetes mellitus (40.6\%) followed by hypertension (37.1\%).In our study, $35.0 \%$ patients were smoker. However, in a study by Uddin $\mathrm{F}$ and HoqueFAK ${ }^{14}, 59.4 \%$ patients were smoker.

In-hospital mortality was $6.6 \%$ in SK group and $31.6 \%$ in non-SK group $(p=0.001)$ in our study. Overall, in-hospital mortality in our study was $16.67 \%$. However, overall higher in-hospital mortality rate i.e. $12.9 \%$ (8.7\% in SK and $20.5 \%$ in non SK group; $p=00.2$ ) was observed in a study by Uddin $\mathrm{F}$ and Hoque FAK. ${ }^{14}$

In our study, Left ventricular failure rate was 8.33\% and $23.33 \%$ in SK and non SK groups $(p=0.001)$, respectively and overall left ventricular failure was $14.34 \%$. However, a higher overall left ventricular failure rate i.e. $20.6 \%$ (17.9\% and $25.4 \%$ in SK and non SK group, respectively) was recorded in a study by Uddin $\mathrm{F}$ and Hoque FAK. ${ }^{14}$
In our study, Mitral regurgitation was observed in $1.11 \%$ and $2.5 \%$ patients in SK and non SK groups $(p=0.848)$, respectively and overall frequency of mitral regurgitation was $1.67 \%$. Similarly, in a study by Uddin F and HoqueFAK ${ }^{14}$, overall mitral regurgitations was 1.67\% (1.11\% and $2.5 \%$ in SK and non SK group, respectively). In our study, $3.33 \%$ and $5.83 \%$ patients were reported with VT/VF in SK and non SK groups $(p=0.297)$, respectively and overall frequency of VT/VF was $4.34 \%$. However, higher VF rate was reported in a study by Taheri $L$ et $\mathrm{al}^{13}$, i.e. $8.7 \%$ and $5.3 \%$ in SK and non SK groups, respectively. In contrary to our study, overall higher VT/VF rate i.e. $7.6 \%(6.0 \%$ and $10.7 \%$ in SK and non SK groups, respectively) was reported in a study by Uddin $\mathrm{F}$ and Hoque FAK. ${ }^{14}$

Complete heart block was $2.22 \%$ and $5.83 \%$ in SK and non SK groups $(p=0.103)$, respectively and overall frequency of Complete heart block was $3.67 \%$ in our study. Similarly, in a study by Uddin $\mathrm{F}$ and HoqueFAK ${ }^{14}$, overall complete heart block was $3.2 \%$ (3.2\% and $3.3 \%$ in SK and non SK groups, respectively). Atrial fibrillation was $0.55 \%$ and $1.67 \%$ in SK and non SK groups $(p=0.343)$ respectively and overall frequency of atrial fibrillation was $1.0 \%$ in our study. In a study by Taheri $L$ et al ${ }^{13}$, atrial fibrillation was $2.7 \%$ and $2.7 \%$ in SK and non SK groups, respectively. However, overall lower atrial fibrillation frequency i.e. $0.3 \%(0.0 \%$ and $0.8 \%$ in SK and non SK groups, respectively) was observed in a study by Uddin $\mathrm{F}$ and HoqueFAK. ${ }^{14}$ Post Ml angina was $3.33 \%$ and $13.33 \%$ in SK and non SK groups $(p=0.001)$, respectively and overall frequency of post $\mathrm{Ml}$ angina was $7.34 \%$ in our study. In a study by Uddin $\mathrm{F}$ and HoqueFAK ${ }^{14}$, overall frequency of post $\mathrm{Ml}$ angina was 6.5\% (5.0\% and $9.0 \%$ in SK and non SK groups, respectively). Re-infarction was $1.11 \%$ and $3.33 \%$ in SK and non SK group $(p=0.001)$, respectively and overall re-infarction was $2.0 \%$ in our study. In a study by Uddin $\mathrm{F}$ and HoqueFAK ${ }^{14}$, overall re-infarction was $0.6 \%(0.0 \%$ and $1.6 \%$ in SK and non SK groups, respectively). CVA was $0.55 \%$ and $0.0 \%$ in SK and non SK group $(p=0.812)$, respectively and overall frequency of CVA was $0.34 \%$ in our study. Similarly, in a study by Uddin $\mathrm{F}$ and HoqueFAK ${ }^{14}$, overall CVA was 
$0.3 \%(0.5 \%$ and $0.0 \%$ in SK and non SK groups, respectively). Ventricular septal defect was $0.0 \%$ and $3.33 \%$ in SK and non SK group $(p=0.029)$, respectively and overall frequency of ventral septal defect was $1.34 \%$ in our study. Similarly, in a study by Uddin $\mathrm{F}$ and HoqueFAK ${ }^{14}$, overall ventricular septal defects was $1.2 \%(0.9 \%$ and $1.6 \%$ in SK and non SK groups, respectively).

Hypotension was $25 \%$ and $8.33 \%$ in SK and non SK group $(p=0.001)$, respectively and overall frequency of hypotension was $18.34 \%$ in our study. Increase incidence of hypotension in SK group was mostly reversed by giving fluids. In a study by Taheri $L$ et $\mathrm{al}^{13}$, hypotension was $10.7 \%$ and $13.3 \%$ in SK and non SK group, respectively.

This study has certain limitations. It was a single center study. Moreover, this requires a larger sample size.

\section{CONCLUSION}

It is concluded that Reperfusion therapy with streptokinase among patients with myocardial infarction was found effective not only in terms of low in-hospital mortality rate but also low rate of post myocardial infarction complications.

\section{Copyright $\odot 17$ June, 2020.}

\section{REFERENCES}

1. Gersh BJ. Myocardial Infarction. Rev Cardiovasc Med 2019; 2(3):174-6.

2. Syed U. Reduction of ST segment elevation in diabetic patients with myocardial infarction after thrombolytic therapy. J Ayub Med Coll 2017; 29(2):308-10.

3. Tourani S, Bashzar S, Nikfar S, Ravaghi H, Sadeghi M. Effectiveness of tenecteplase versus streptokinase in treatment of acute myocardial infarction: A metaanalysis. TUMJ 2018; 76(6):380-7.

4. Rezapour A, Hadian M, Ghasemi M, Vahedi S, Jafari A. Economic evaluation of the drugs used in treating patients with myocardial infarction: A Systematic review. JHMI 2019; 6(1):7-14.

5. Sameni M, Gholipourmalekabadi M, Bandehpour M, Hashemi M, Sahebjam F, Tohidi V, Kazemi B. Evaluation of in vivo bioactivity of a mutated streptokinase. NBM 2017; 5(2):71-7.
6. Usman M. Door to needle time in acute myocardial infarction patients. JRMC 2017; 21 (2):127-30.

7. Yazdi AH, Khalilipur E, Zahedmehr A, Pouya SA, Pakrou M, Ghaznavi MA, Mikaelvand A, Rouzitalab M. Fibrinolytic therapy with streptokinase vs tenecteplase for patients with ST-Elevation MI not amenable to primary PCI. Iran Heart J2017; 18(2):439.

8. Mathur R, Yadav P, Sanghvi S, Sarda P, Baroopal A, Mahajan S. Evaluation of clinical outcome of thrombolytic therapy in elderly patients in Western Rajasthan: A single centre experience. IntJ Res Med Sci 2019; 7(10):3773-7.

9. Sangaré Z, Traoré AK, Doumbia M. Evaluation of thrombolysis in the management of St-Elevation myocardial infarction (STEMI) in isolated cardiology unit. CardiolVasc Res 2017; 1(1):1-4.

10. Ramya NS, Narendra JB, Raghavulu V, Babu MS, Teja ND, Malini KH, Prathap SS. Assess the clinical efficacy of streptokinase in thrombolysed patients of acute ST segment elevation myocardial infarction. JYP 2018; 10(3):330-3.

11. Iqbal S, Bari MS, Bari MA, Islam MM, Majumder MA, Islam Z, Aditya GP, Paul GK, Shakil SS, Saha B, Paul PK. A comparative study of ST segment resolution between diabetic and non-diabetic ST segment elevation myocardial infarction patients following streptokinase thrombolysis. Cardiovasc J. 2019; $11(2): 118-22$.

12. Kumbhani DJ, Alexander T, Nallamothu BK, Menon V, Ayers C, Mullasari AS, TN-STEMI Investigators. Pharmacoinvasive approach with streptokinase in low to intermediate risk ST-Elevation myocardial infarction patients: Insights from the tamil NaduSTEMI initiative. Am J Cardiovasc Drug 2019; 19(5):517-9.

13. Taheri L, Zargham-Boroujeni A, Jahromi MK, Charkhandaz M, Hojat M. Effect of streptokinase on reperfusion after acute myocardial infarction and its complications: An ex-post facto study. Glob J Health Sci2015; 7(4):184-9.

14. Uddin F, Hoque AF. Outcome of patients having acute myocardial infarction with and without streptokinase. Med Today 2019; 31(2):68-71.

15. Roxana Sadeghi, Nadia Adnani Premature coronary heart disease and traditional risk factors Int Cardiovasc Res J. 2013 Jun; 7(2): 46-50. 


\begin{tabular}{|c|l|l|l|}
\hline \multicolumn{3}{|c|}{ AUTHORSHIP AND CONTRIBUTION DECLARATION } \\
\hline Sr. \# & \multicolumn{1}{|c|}{ Author(s) Full Name } & Contribution to the paper & Author(s) Signature \\
\hline 1 & Fida Muhammad & 1st Author \\
\hline 2 & Amir Nazeer & 2nd Author \\
\hline 3 & Sheraz Saleem & 3rd Author \\
\hline 5 & Nighat Fatima & Shahzad Aslam & 5th Author \\
\hline
\end{tabular}

